Taking $x, y$, as perpendicular sides,

Thus

$$
x+y+\sqrt{\left(x^{2}+y^{2}\right)}=n x y .
$$

Therefore

$$
\left.\begin{array}{c}
(x+y-n x y)^{2}=x^{2}+y^{2}, \\
n^{2} x y-2 n(x+y)+2=0, \\
(n x-2)(n y-2)=2=z \times \frac{2}{z} \\
n x=2+z, \quad n y=2+\frac{2}{z} \\
x: y=(2+z):\left(2+\frac{2}{z}\right)
\end{array}\right\}, \begin{aligned}
& z \text { is any rational } \\
& \text { number. }
\end{aligned}
$$

This proof is a simple piece of work which would interest many pupils in the higher forms of the secondary school, and might be discovered by some pupils. But it can be further simplified for more pupils by making $n$ equal to $\frac{1}{2}$. The problem then becomes,

"To find a triangle which contains as many square units as there are units in the perimeter."

The ultimate equation is then;

$$
(x-4)(y-4)=8 \text {. }
$$

Taking only whole number factors of 8 , the roots are :

$$
\begin{array}{ll}
x=4+1, & y=4+8, \quad \text { i.e. triangle } 5 / 12 / 13, \\
x=4+2, & y=4+4, \quad \text { i.e. triangle } 6 / 8 / 10 .
\end{array}
$$

These are the only two whole number solutions.

R. S. Williamson.

\title{
CORRESPONDENCE.
}

\section{THE NAME OF THE GAME OF NIM.}

To the Editor of the Mathematical Gazette.

Sir,-OOn p. 119 of the May, 1953, issue of the Mathematical Gazette I read the conjecture by Professor Alan S. C. Ross that Professor C. L. Bouton derived the name of the game "Nim" from the imperative singular of the German verb nehmen. I am writing to verify this conjecture. Professor Bouton was a teacher of mine, and later I became his colleague. I was a frequent visitor in his home. He had had numerous mathematical and personal contacts with Germany, and received his Ph.D. from Leipzig in 1898. I distinctly recall his saying to me that he had chosen the name from the German word " nimm", as a word that might well be used frequently during the play of the game, but had dropped the final " $\mathrm{m}$ ".

$$
\text { Yours, etc., }
$$

University of Harvard.

J. L. WALSH

1754. Launching by catapult and the use of arrester gear followed standard aircraft-carrier practice, but the idea of placing on the ground, instead of in the aircraft, the means of absorbing the vertical kinetic energy on landing was entirely new.-The Times, report of Sir Ben Lockspeiser's British Association address, September 1952. [Per Mr. F. Puryer White.] 